\title{
A VIAGEM DE PEDRO ÁLVARES CABRAL SOB O PONTO DE VISTA NÁUTICO.
}

Em 1850, numa das sessões do Instituto Histórico e Geográfico Brasileiro, com sede no Rio de Janeiro, o sócio Joaquim Norberto de Sousa e Silva, baseando-se principalmente em um dos tópicos da carta que Mestre João escreveu de Pôrto Seguro a $1 .^{\circ}$ de maio de 1500 ao rei $\mathrm{D}$. Manuel, concluiu a sua conferência afirmando ter sido o Brasil descoberto intencionalmente por Alvares Cabral, quando da sua viagem para Calicute (1) .

Conta-nos o mestre Capistrano de Abreu que, mais tarde, Joaquim Norberto declarou que com a sua tese apenas quis semear dúvidas, mas essas dúvidas transformara-se, por assim dizer, em certeza, e hoje é quase dogma em Portugal que o descobrimento do nosso país não foi fortuito (2) .

Aqui, entre nós, por afinidade de raça e a pretexto de estar a par da última novidade, não é pequeno o número dos prosélitos dessa tese. Porém, exclusão feita de Portugal e do Brasil, em nenhum país do mundo encontra-se um só historiador de renome que espose a tese do descobrimento intencional do nosso país por Alvares Cabral, o que é muito significativo.

Exgotadas as argumentações baseadas na documentação histórico-cartográfica, os defensores da tese da intencionalidade se apegam agora ao estudo náutico da viagem da segunda armada portuguêsa da Îndia. Vejamos, pois, se com tal estudo evidenciado fica ter Alvares Cabral descoberto o Brasil intencionalmente.

Todos os historiadores estão de pleno acôrdo que o comandante da referida frota, ao partir da altura das ilhas do Cabo Verde em demanda do cabo da Boa Esperança, se afastou em demasia para Oeste da rota que Vasco da Gama lhe tinha aconselhado, pelo que, a 22 de abril de 1500 , arribou ao litoral brasileiro, cêrca de 17 graus de latitude Sul.

(1). - Revista do Instituto Histórico e Geográfico Brasileiro, tomo XV, segunda edição, 1888, páginas 152 a 204 .

(2). - o Descobrimento do Brasil, Rio de Janeiro, 1929, página 303. 
Os partidários do descobrimento intencional do Brasil são de parecer que êsse afastamento foi proposital e "que Cabral e seus pilotos tinham a consciência unânime dêsse afastamento". (3). Mas a discussão havida em Pôrto Seguro entre os pilotos, e entre Mestre João e o pilôto Pero Escolar, evidencia que, em absoluto, não havia a apregoadä "consciência unânime do afastamento" (4).

Os adeptos, como nós, do encôntro casual opinam que o capitão-mor, contra a sua vontade e ignorando o afastamento, foi arrastado pela corrente equatorial à costa de uma terra situada ao ocidente do continente negro, cuja existência ignorava.

O que, pois, importa saber, é se a frota de Alvares Cabral, contra a sua vontade, podia ou não ser arrastada pela referida corrente marítima ao litoral brasileiro. No caso afirmativo, a tese da intencionalidade ficará muito abalada, uma vez que a sua pretensa defesa está na parte náutica da questão.

$\mathrm{O}$ assunto a ser debatido, dizendo com a náutica, escapa à nossa competência. Dêsse modo tivemos necessidade de apelar para uma grande autoridade em navegação à vela, tal seja o erudito historiador e almirante norte-americano Samuel Eliot Morison que, por uma excepcional gentileza, nos autorizou a traduzir e a dar publicidade ao seu estudo náutico provando sobejamente a possibilidade de ter sido Cabral arrastado pela corrente equatorial à costa brasileira. O estudo de Morison é o seguinte, com as anotações do próprio autor (5) .

"Instruções dadas por Vasco da Gama a respeito da rota de Cabral e com relação ao seu modo de agir durante a viagem, existem sob a forma de notas tomadas por um escrivão da côrte à vista do aconselhado pelo grande navegador" (6).

(3). - Jaime Cortesão, A Carta de Pero Vaz de Caminha, Rio de Janeiro, 1948, página 76.

(4). - Carta de Mestre João ao rei D: Manuel, datada de Pórto Seguro em 1.0 de maio de 1500 (...por lo qual sabra vosa alteza que todos los pylotos van adiante de mi en tanto que Pero Escolar va adiante 150 leguas $e$ otros mas e otros menos...").

(5). - o estudo de Morison intitula-se: Da Gama's Instructions and the Baning Route to India e está publicado no seu erudito livro tantas vêzes por nós citado: Portguese voyage to America in the Fifteenth Century, Cambridge, 1940 .

(6). - Este documento foi descoberto por Varnhagen e um fac-símile foi publicado em sua História Geral do Brasil (Rio de Janeiro, 1854). Fac-símile e texto português foram estampados com comentários pelo Dr. Antônio Baiāo na História da Colonização Portuguêsa do Brasil. o Dr. Baiāo levantou alguma dúvida sôbre a sua autenticidade, por julgar que êsse documento não podia ser encontrado na Tôrre do Tombo; mas tónou-se depois diretor dêste arquivo português, encontrou o terto original conforme me contou. Tradução em Greenlee, páglnas 167 e 169. 
"Cabral recebe ordem de velejar diretamente para a ilha de Santiago do arquipélago de Cabo Verde, sem precisar nela tocar, no caso de ter água suficiente para quatro meses. Dali navegaria com alísios $\mathrm{NE}$ à proa, para o Sul e, se tivesse necessidade de guinar, fôsse para Sudoeste".

"Quando apanhasse os alísios SE pela proa, devia velejar tão junto quanto possível ao vento e à corrente, até ficar o cabo da Boa Esperança completamente a Este".

"Dêsse modo a navegação seria mais rápida, os mantimentos se conservariam melhor e a gente iria mais sá e os navios ficariam defendidos do gusano. Se alguns navios desgarrassem da frota depois de deixar as ilhas de Cabo Verde, deviam se encontrar na Aguada de São Brás, antiga aguada de Dias na atual baía de Mossel, cêrca de 150 milhas a Este do Cabo das Agulhas".

"Não há menção de nenhum desembarque no Brasil, ou em qualquer outro ponto, antes de dobrarem o cabo da Boa Esperança" (7).

"A existência de tais instruções não afasta a possibilidade de "instruções adicionais e secretas" do rei a Cabral para tocar no Brasil. Não posso ver nenhum objetivo ou necessidade de sigilo do Brasil naquele tempo".

"Nessas admiráveis instruções é Cabral aconselhado a seguir aproximadamente a mesma rota recomendada hoje em dia pelo Departamento Hidrográfico dos Estados Unidos e pelo Almirantado Britânico aos navios de vela que partem nos meses de abril e maio, da Europa setentrional para além do cabo da Boa Esperança".

"Essas instruçôes revelam quão cuidadosas eram as observações de Gama, Dias e da geração de navegadores portuguêses que os precederam nas viagens da Guiné; pois o melhor caminho de regresso, da Guiné a Portugal, era descer até o Equador ou ir além, a fim de apanhar os alisios SE e a corrente equatorial. E' admissível supor-se ter sido o Atlântico Sul explorado pelos

Trađução completa, por mim feita, com notas e mapas, pode ser encontrada no Mariner's Mirror, XXIV (outubro, 1938), páginas 402 a 408.

Nota do tradutor. Na publicação do Ministério das Colônias da República Portuguêsa intitulado Os Sete Unicos Documentos de 1500 Referentes à Viagem de Peđro Alvares Cabral, Lisboa, 1940, páginas 19 e 20, o historiador português A. Fontoura da Costa traduziu para o português moderno êsse documento.

(7). - Nota do tradutor. Reputamos de grande importância esta observação de Morison, porque vem provar que, mesmo em caso de emergência, nāo era recomendado a Cabral tocar em qualquer ponto do litoral brasileiro, prova evidente da mais completa ignoráncla da existência de terras ao ocidente'da Africa. 
portuguêses até 5 graus de latitude $S$ e 20 graus de longitude $O$ de Greenwich, durante as viagens regulares que realizaram à Guiné" (8).

"Vasco da Gama, partindo das ilhas de Cabo Verde a 2 de agôsto de 1497, cometera o êrro natural de navegar a Sudeste, diretamente para o cabo da Boa Esperança. Parece que êle pretendia atravessar o gôlfo da Guiné em rumo direto. Dêsse modo caiu na faixa da monção SO cheia de tornados, perdeu a verga grande e teve a corrente equatorial pela proa" (9). Daí por diante, é o que geralmente se supõe, aproveitou os alisios de SE da maneira que recomenda a Cabral, a fim. de atingir o mais ràpidamente possivel a faixa ocidental; mas levou três meses e um dia para avistar terra, a da baía de Santa Helena, África do Sul" (10).

"A razâo, porque Gama aconselhou Cabral a navegar para o Sul das ilhas de Cabo Verde e para Oeste do Sul uma vez que êle não pode seguir bem tal rota, é claro. Um navio de vela deve evitar a navegação ao Este das ilhas de Cabo Verde nessa estação, se não quiser cair na zona das calmas equatoriais e ser arrastado pela corrente da Guiné para o gôlfo do mesmo nome. Por outro lado, o navio não deve se dirigir muito para o Oeste do Sul, se não desejar que os alísios de SE o apanhem num ponto onde, tendo a corrente equatorial pelo lado da proa que dá para o vento, seja arrastado a sotavento do cabo de São Roque e obrigado a velejar para trás em tôrno dêsse formidável obstáculo. E' sabido que navios, apanhados a sotavento na saliên-

(8). - J. W. Blake, European Beginnings in West Africa, páginas 13 e 14. O próprio sucesso da viagem de Vasco da Gama e o acêrto de suas instruçōes, serviram para justificar viagens anteriores e "secretas" ao Cabo e ao Brasil. No entanto, julgo que a experiência das viagens à Guiné e o gênio de Vasco da Gama, são suficientes para explicar o seu sucesso. Caboto, também empreendeu viagem no mês em que os ventos de Este são mais freqüentes no Atlântico Norte e fêz uma notável travessia. E, finalmente, Magalhães decobriu o caminho pelo estreito que conserva o seu nome, apesar de hoje em dia serem poucos os navios que se aventuram a atravessá-lo; depois disso, continuou a sua vingem através do Pacífico seguindo uma rota que só com dificuldade pode ser melhorada. Não'se pode negar a hipótese de que "viagens secretas portuguêsas" tenham antecedido às de Cabral, Colombo e talvez a de Caboto, até os seus respectivos destinos, e assim tenham indicado a êstes navegantes as verdadeiras rotas. Suponhamos, de acôrdo com tal raciocínio, um grupo de escoteiros marítimos portuguêses, antecedendo cada grande descoberta marítima, até mesmo a viagem de Magalhães!

(9). - Veja o mapa da média das direçōes dos ventos para agôsto no Ocean Passages for the Wold, pelo contra-almirante B. T. Somerville (Londres, 1923). Não são as mesmas que as do nosso mapa, indicando a viagem de Cabral em abril e malo.

(10). - Journal of First Voyage of Vasco da Gama (E. G. Ravenstein, editor Hakluyt Soc. XCIX, 1898), páginas 3 a 5, 187-90, e mapa. Existem muítas controvérsias quanto à verdadeira rota de Gama . 


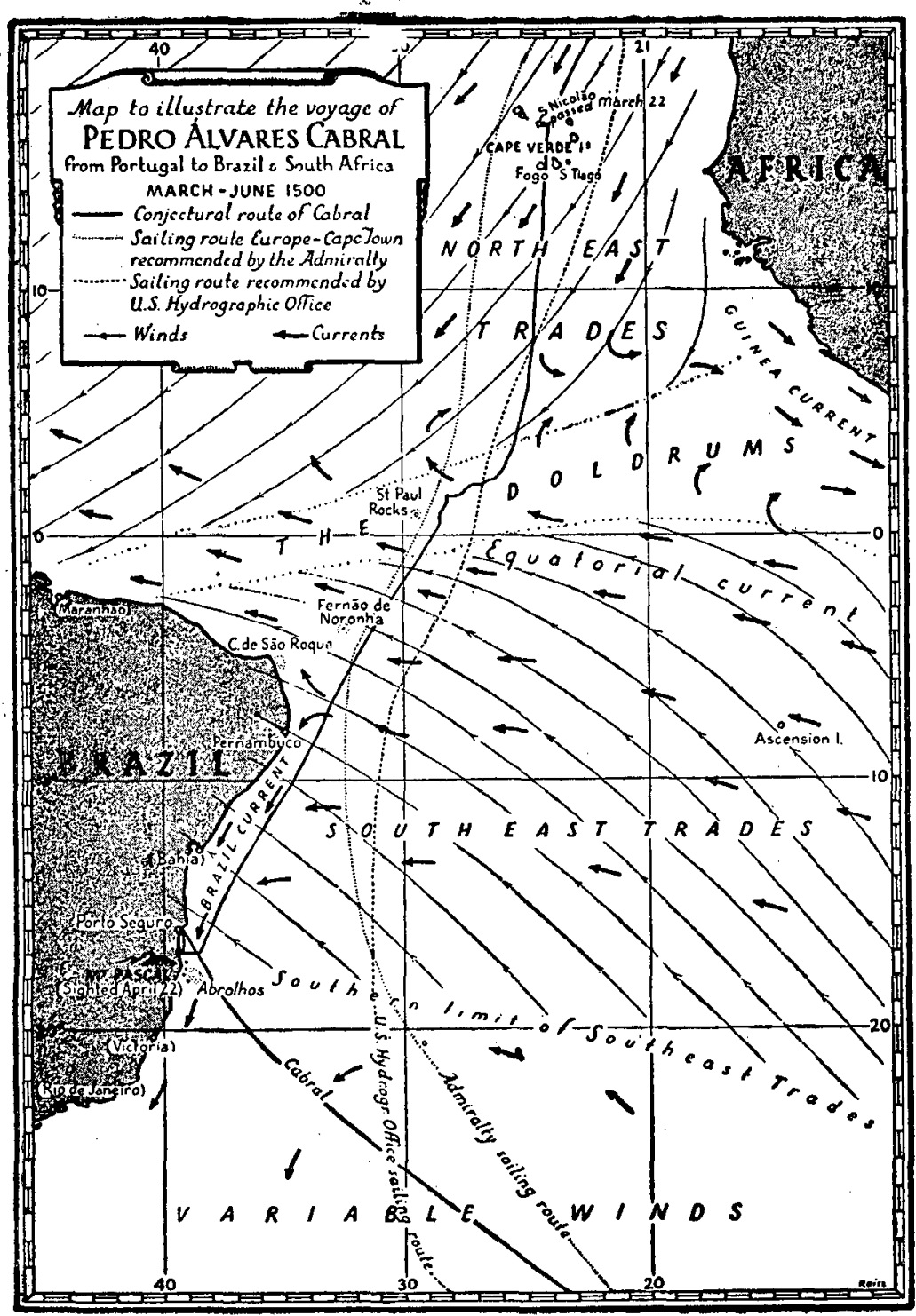


cia do cabo de São Roque, se têm debatido semanas a fio na corrente equatorial, ou então se têm voltado para o norte, a fim de novamente começar a dobrá-lo".

"Um navio que dobre com felicidade êste cabo, tem a corrente do Brasil a seu favor e navegará tanto ao Sul, quanto lhe permitirem os alíseos e o feitio de suas velas. E, depois de entrar na zona dos ventos variáveis, êle iniciará a sua rota oriental para o cabo da Boa Esperança. Foi isso que Vasco da Gama aconselhou e foi isso que Pedro Álvares Cabral fêz, conforme a sua capacidade" (11).

"O capitão J. C. Ross, em sua viagem de descobertas em direção à zona Antártica, de 1839-1840, cruzou - Equador a 3 de dezembro de 1839 , na longitude de 30 graus $O$, mas aconselhou os vindouros a cruzá-lo 3 ou 4 graus mais para Este, visto que "a corrente ocidental é capaz de aproximar em demasia os navios da costa do Brasil" (12).

"Mateus Maury, depois de examinar centenas ou mesmo milhares de diários de navegação de navios a vela, aconselhou os capitães de navios que partem de Nova York ou do Canal da Mancha, com destino ao cabo da Boa Esperança, a navegarem a um ponto que fica ao Oeste dos Açores para então enfrentarem o S com os alísios NE, e cruzarem o Equador não mais ao Oeste, do que a 30 graus de longitude $O$ de Greenwich" (13). "Em outras palavras: êste grande cientìsta não pode achar rota melhor do que aquela aconselhada por Vasco da Gama a Pedro Álvares Cabral em 1500". "E até hoje, não se encontrou caminho melhor".

"As últimas prescrições do Almirantado Britânico para velejar nessas águas em abril, são instrutivas. "Cruzar a 5 graus de latitude Norte, entre 25 a 28 graus de longitude $O$, e o Equador entre 28 e 31 graus $O^{n}$. Isto significa uma rota SSO (real), pouco mais ou menos a partir da ilha que Cabral passou sem tocar. "Depois de cortar o Equador como se recomenda", continuam as modernas instruções do Almirantado Britânico, "o navio deverá atravessar a zona dos alisados SE com o vento a

(11). - Duarte Pacheco Pereira, escrevendo em 1505, Indica uma rota partindo das llhas (de Cabo Verde) até a latitude de 19 graus e daí ESE para dobrar o Cabo. Isto não é tão detalhado como as instruçōes de vasco da Gama, mas qualquer sensato mestre de navio navegaria ao Oeste do Sul nessa rota, no caso de não poder navegar bem na direção Sul, ị̣. portando isso na mesma coisa. Esmeraldo de Situ Orbis (Kimble ed.), p. 170 .

(12). - Trecho em W. H. Rosser, Short Notes and Sailing Directions, with Remarks ond Making Passages (3 ed., Londres, 1900), p. 30.

(13). - M. F. Maury, Explanations and Sailing Directions to Accompany the Wind and Current Charts (8th ed., Washington, 1858-1859), 11, 143-356, 368-445. 
borbordo apesar da possibilidade de se desviar para $O$ pelo $S$, pois o vento o arrastará mais para o oriente à medida que êle avançar, e finalmente para Este no limite meridional dos alísios" (14). Os navios devem velejar o mais próximo do Sul que o vento permitir, até deixarem a faixa dos alísios $\mathrm{SE}$ entre 18 e 22 graus de latitude $\mathrm{S}$, para apanharem aquêle dos variáveis".

"A partir da ilha da Trindade, a qual fica na latitude de 20 graus e 30 minutos $\mathrm{S}$ e na longitude de 29 graus e 50 minutos $O$, ilha que não aconselhamos os navios atingir a fim de acertar os seus cronômetros, deve-se estabelecer uma rota para SE a fim de cruzar o paralelo de 30 graus $S$ na longitude de 22 graus $O$, pouco mais ou menos, e a fim de cruzar o meridiano de Greenwich na latitude de 35 ou 37 graus S, aproximadamente. Entre êsse ponto e o cabo da Boa Esperança, predominam geralmente ventos de Oeste e do Sul".

"A rota para velejar da Europa "com destino aos portos sul-americanos, cabo Horn e com destino ao cabo da Boa Esperança e Oriente" (notai sua identidade), indicada na "Carta do Pilôto do Atlântico Norte" para abril de 1938, publicada pelo Departamento Hidrográfico dos Estados Unidos, é quase a mesma do Almirante Somerville. Duas rotas alternadas, uma passando Tenerife e continuando dentro das ilhas de Cabo Verde; a outra fora de tôdas as ilhas dêste arquipélago: convergem ambas em 1 grau de latitude $\mathrm{S}$ e 22 graus de longitude $O$, cêrca de 180 milhas a $S E$ dos rochedos São Paulo. Ali é a rota alterada para SSO. Na "carta do Pilôto do Oceano Atlântico Sul" para março, abril e maio de 1938, a rota para o cabo da Boa Esperança dei$x a$ a do rio e cabo Horn a 5 graus de latitude $S$, e se inclina gradualmente para o Sul, passando a Trindade e voltando-se para Este a 25 graus de latitude Sul".

"E' de notar que essas informações e rotas não aconselham tocar na costa brasileira; a rota dos Estados Unidos passa a 230 milhas a Este de Penambuco. Este fato tem servido aos partidários da intencionalidade para provar que se Cabral descobriu o Brasil, fê-lo de caso pensado. $O$ que tais navegadores de gabinete parecem ignorar é que todos os portulanos e tôdas as cartas com rotas estabelecidas, não passam de aproximações. Como diz o almirante Somerville em seu mapa de Rotas Mundiais para Navegação a vela, "as rotas indicadas têm por base experiências usuais mas, devido à variabilidade de ventos em tôdas as latitudes, o abandôno dos roteiros aqui recomendados pode tornar-se necessário?.

(14). - Somerville, Ocean Passages for the World (Londres, 1923), p. 443. A edição de 1933 é citada por Greenlee, na introdução da sua obra. 
Grifei parte dêste sábio conselho a bem das pessoas que imaginam que os alísios são absolutamente invariáveis, permitindo assim a um navio de vela navegar diretamente ao seu destino, como um navio a vapor. Os alísios são bastante moderados para o navio que navega independentemente, mas não para o navio que navega dependendo do vento como os de Cabral. Mesmo uma variação diuturna de 45 graus não é raro, como pessoalmente observei. Assim um navio de vela a caminho do cabo da Boa Esperança, com as velas amuradas por bombordo e velejando à bolina (como Gama aconselhou em 1500 e o almirante Somerville em 1933), pode desviar-se algumas centenas de milhas da rota normal, conforme fôr o vento: contrário ou a favor. Bernardino Escalante, autor dum sumário de história marítima portuguêsa, em 1577, refere-se a isto de modo claro. Como diz o seu tradutor Elizabethan ao descrever o caminho marítimo da India: "Embora o cabo da Boa Esperança ficasse a Sudeste, não podiam êles velejar bem porque nesses mares há muitos levantes que são ventos de Este-sudeste e Sudeste, que faziam desviar demais para perto da costa do Brasil, e por isso êles navegavam à bolina (15) para o Sul-sudeste, Sul e sudoeste, conforme o vento e o tempo Ihes permitiam, até alcançarem 36 graus, por vêzes à vista das ilhas de Tristão da Cunha... até encontrarem ventos oocidentais, com os quais voltavam a navegar para Este ou Este-nordeste para atingir o Cabo" (16) .

"Milhares de navios navegaram nas mesmas direções para passar dos alísios NE para o de SE com um minimo de calmaria, e passar dos alísios de SE para os variáveis com um mínimo de desvio para Oeste. Centenas dêles foram arrastados para o litoral brasileiro ou para muito próximo dêle. Visto haver sido feitas declarações categóricas de não ter isso jamais acontecido, eu desêjo dar alguns exemplos tirados das viagens de três séculos para provar que isso podia acontecer e sucedeu em viagens normais, sem nenhuma tempestade nem quaisquer outras circunstâncias fora de comum".

"João de Castro comandando o Grifo numa viagem à India em 1538, passou entre as ilhas de Cabo Verde e a costa africana a 22 de abril e entrou no gôlfo da Guiné, como muitos marinheiros fizeram antes de ser provado que esta rota não servia. Apesar de vários dias

(15). - Tão junto ao vento quanto possível.

(16). - A Discourse of the navigation which the Portugales doe make to the Realmes and Prouinces of the East partes of the Worlde... written by Bernardine Escalanta... translated out of Spanish into English by John Frampton (Londres, 1579), fôlha 9. A edição original foi Impressa em Sevilha em 1577. 
de calmarias, o Grifo manobrou de modo a cortar o Equador cêrca de 14 graus de lontitude 0 a 12 de maio, navegando SO por S com ventos alísios de SE. Embora obtivesse êsse navio latitude meridional excepcionalmente boa antes de apanhar os alisios de bombordo, esta rota o levou a 27 de maio a 60 léguas da costa brasileira a 17 graus de latitude $S$ que foi aproximadamente a que atingiu Cabral na sua descoberta. No dia seguinte essa nau apanhou os ventos de Oeste e começou a sua derrota para Este" (17).

"Jan Huyghen van Linschoten, que embarcou para a Índia em abril de 1583 no São Salvador, um dos navios da frota portuguêsa, escreve em seu Itenarário (segundo o tradutor inglês de 1598) que os navios portuguêses, depois de cruzarem a zona das calmarias e o Equador: "encontram um vento que denominam vento geral, e é de Sudeste, porém de costado, e precisam ficar sempre obliquamente ao vento quase até chegarem ao (latitude do) cabo da Boa Esperança; e por existirem na costa do Brasil, cêrca de 18 graus, ao $S$ (da linha equinocial), grandes baixios, a que os portuguêses chamam Abrolhos, que avançam 70 milhas pelo mar da banda direita, para evitá-los os navios se aproximam muito da costa da Guiné, e assim evitam os ditos baixios, de outro modo regressam a Portugal, e muitas vêzes com perigo de se perderem, como aconteceu ao nosso navio Almirante Saint Philip, que no ano de 1582 atingiu durante a noite os balxios, e correu grande perigo de se perder. Todavia se safou, e velejou de retôrno a Portugal e, nesse mesmo ano, para evitar os baixios, êle se aproximou tanto da costa da Guiné onde, por causa da grande calmaria e das chuvas, foi forçado a ir daqui para ali durante dois meses, antes de poder passar a linha (Equinocial), chegando à India dois meses depois dos outros navios. Por isso os homens precisam tomar cautela para não se aproximarem em demasia da costa, a fim de evitar as calmarias e tempestades, e nem se afastarem demais dela para evitar os baixios e bancos em que consiste a viagem indiana intei-

\footnotetext{
(17). - Joāo de Castro, Roteiro de Lisboa a Goa (J. de Andrade Corvo, ed. Lisboa, 1882), páginas 76-165.

Nota do tradutor. O ocorrido com o navio Grifo, a que se refere Morison, foi assim descrito por João de Castro no seu roteiro: "O mestre tomou o sol ao meio dia, e ficou am altura de 17 graus; e assim êle com todos os marinheiros que carteavam, se faziam havia já três dias, com terra; sòmente eu c um marinheiro estavam 60 léguas dela: este dia me disse o pilóto que as águas corriam muito para o sul, que havia muitos dias que o tinha experimentado, e querendo-mo mostrar, ora fôsse por me saber mal declarar, ora por eu não saber entender, mo não pode parecer; e querendo-se por, o sol, vimos um Rabiforcado s6, e havia já dez días que nos desapareceram estas aves". Agência Geral das Colónias, Roteiro de D. Joâo de Catro, Roteiro de Lisboa a Goa, (1538), Lisboa, 1940, página 57.
} 
ra". "A 12 de junho passamos pelos baixios e bancos do Brasil, motivo pelo qual nossos homens ficaram excessivamente alegres, pois agora tínhamos certeza de que desta vez não retrocederíamos para Portugal, como fizeram muitos..." (18).

"Esta frota, na qual navegava Linschoten, não vira terra desde que deixara a costa da Guiné. Assim o São Filipe encalhou em 1582, e o São Salvador fêz sondagens em 1583 muito próximo da terra descoberta por Cabral; e em vez de desejarem atingir a costa neste ponto, fizeram todo o possivel para evitar isso. Os baixios de que fala Linschoten - Parcel das Paredes e Abrolhos -, são extensos bancos cheios de rochedos que começam a menos de 10 milhas ao longo da costa e vinte milhas dela afastada (19). Cabral foi muito feliz em atingir o Monte Pascoal e evitar êsses perigosos bancos de recifes".

"O navio britânico da fndia Oriental, o Kent, partiu de Portsmouth a 4 de junho de 1764 , levando distintos passageiros, entre os quais Lord Clive. A 24 de julho os alísios NE o deixaram a 5 graus de latitude $\mathrm{N}$ e a 22 graus de longitude $O$. Quando o navio apanhou os alísios SE, êstes não lhe permitiram dobrar o cabo de São Roque e, achando-se em mar raso, perto do banco, com o cabo à vista, virou a estilbordo, velejando para Nordeste. A perda de mastareus permitiu à corrente equatorial arrastálo tanto a sotavento que, na tentativa seguinte, êle foi ter, a 20 de agôsto, exatamente no mesmo ponto, perto do cabo de São Roque. Dirigiu-se outra vez para Nordeste, avistou os rochedos São Paulo, e só se aventurou a virar para aproveitar o vento dum outro lado, a 8 de setembro, quando já atingira 3 graus de latitude $N$ e 18 graus de longitude $O$. Desta vez os alisios sopraram do Oriente, e tudo correu bem até o Kent alcançar 19 graus de latitude $S$, cêrca de 350 milhas da costa brasileira. Neste ponto foi êle apanhado por um furaco ocidental que o arrastou para a Trindade, onde chegou a 28 de setembro. $O$ vento virou outra vez para Este e o pobre Kent foi arrastado para o Rio de Janeiro, onde permaneceu de 7 de outubro a 27 de novembro. Dali fêz êle "rápida viagem" de 34 dias ao cabo de Boa Esperança, ancorando na $\mathrm{Ci}$ dade do Cabo a $10^{\circ}$ de janeiro de 1765 . Partindo daí a 10 do mesmo mês, o Kent alcançou a enseada de Madras a 10 de abril" (20).

(18). - Voyage of J. H. Van Linschoten to the East Indies (Hakluyt Society, LXX, 1885), páginas 15-16, 18.

(19). - British Admiralty, South American Pilot, Part. 1 (1864), pp. 104-106.

(20). - Sir George Forrest, Life of Lord olive (1918), 11, 245-255. 
"Muitos outros exemplos poderiam ser citados (21), mas êstes bastam para provar que um navio de vela, partindo da Europa com destino ao Oriente, pode, sem querer, atingir a costa brasileira, mesmo só algumas milhas da terra de Cabral; mesmo até o cabo Frio, ao Sul. De que valem então as categóricas afirmativas de tantos almirantes de gabinete, segundo as quais Cabral jamais poderia chegar ao Monte Pascoal por acaso; que a descoberta casual daquela parte do Brasil é coisa absurda, impossível, é "êrro inconcebível no ano de 1500, quando os portuguêses tinham quase um século de experiência na arte de navegação?" (22). Eu não afirmo que a descoberta de Cabral tinha de ser casual; mas insisto em afirmar que os fatos são perfeitamente compativeis com a luta de Cabral contra ventos e correntes e dai avistar êle - Monte Pascoal sem suspeitar de terra e sem desêjo de descobrí-la".

"Forçoso é notar que o roteiro de Cabral era $\lrcorner$ melhor que êle podia seguir para atingir a india em tempo mínimo. Isto, e não a descoberta do Brasil, era o objetivo principal de sua viagem. Nada há de mais maravilhoso e digno de ser louvado de que haverem os portuguêses (depois de uma viagem ao Cabo, aquela de Dias, próximo da costa africana, e outra, a de Gama, dela afastada), descoberto os meios de utilizarem do melhor modo

(21): - Exemplos: o capitão Will Sproul de South Bंristol, Maine, informou-me que numa viagem de Nova York a Buenos Aires, em 1917, na escuna Martha T. Small foi forçado a deitar ferros em Cabo. Frio, em setembro, porque os ventos alísios vinham tão do Sul a ponto de não poder dobrá-lo. Meu amigo Lincoln Colcord, que fêz diversas viagens à China com seu pai em 1890 e 1900, escreveu-me lembrando-se de ter avistado por duas vêzes a costa do Brasil perto de Pernambuco, sem que tivesse intenção, pois estavam apenas procurando fazer o melhor possível com o vento a bombordo, na rota pré-estabelecida. A mesma coisa aconteceu ao meu pai em 1903 no barco Nuuanu, capitão Josselyn, viajando para Havaí. A tendência do vento correntes faziam ocasionalmente avistarem o Brasil, o que era inevitável, às vêzes, mesmo nos melhorados square-riggers do fim do século XIX, que podiam navegar cêrca de dois pontos mais perto dos ventos que a frota de Cabral. Nota do tradutor. o historiador português Jaime Cortesão (História de Portugal, Edição Monumental, Barcelos, 1932, volume IV, página 138) escreve o seguinte: "Já no regimento de Afonso de Albuquerque, em 1503, se considerava como um acidente natural que as naus a caminho da india avistassem terras do Brasil..." "se vos achasseis pelo caminho que fizerdes tão chegado à ilha da Cruz (Brasil) podeis ir. a ela e aí tomar água e lenha" (Cartas; 111, 186)... "Das armadas que partiram anualmente, depois de Cabral e até 1507, e de cujas viagens se conhecem relatos mais ou menos minuciosos, sabe-se que, por via de regra, avistaram terras do Brasil ou algumas ithas próximas da costa brasileira. E o mesmo sucedeu com a expedição francesa de Gonneville que, havendo partido em 1503 para a fndia, foi ter às costas do Brasil. Daí por diante crônicas e roteiros referem, com freqüência, o mesmo fato".

(22). - Fidelino de Figueiredo, na The Hispanic American Historical Review, VI, 60 . 
possivel os fortes ventos do Atlântico Sul! Vasco da Gama não sòmente abriu o caminho marítimo para a India, como também o melhor, aquêle que tem sido seguido pelos navegantes desde aquêle tempo até hoje (23), rota que é aconselhada pelo Almirantado Britânico em suas últimas instruções sôbre navegação. Este fato, quando fôr devidamente apreciado, acrescentará mais uma fôlha aos louros de um dos maiores navegadores. Pedro Alvares Cabral não é comandante naval da classe de Vasco da Gama, mas revelou bom senso aceitando os seus conselhos. Cabral conduziu sua frota admiràvelmente, e a sua viagem foi uma das mais importantes da história moderna. A opinião de não passar Cabral de simples boneco, levando consigo um esquema de antemão traçado, é ofensa à sua memória".

"Coisa interessante. Passei, graças a êste estudo, a ter de Gama e de Cabral, como navegadores, opiniāo muito mais elevada do que dêles têm seus próprios sucessores na marinha portuguêsa. O almirante Gago Coutinho, por exemplo, pensa que o herói dos Lusíadas $€$ o descobridor do Brasil não eram bastante inteligentes para realizar as viagens que fizeram, sem "viagens secretas" que lhes descobrissem o caminho (24). Como outros historiadores portuguêses, êste almirante deseja tanto provar o propósito que não admite aventura Devido a alguma razão psicológica que eu não posso adivinhar, parece-me coisa bastante irritante aos descendentes dos Gama e CôrteReais a sugestão de haverem seus antepassados descoberto algo por acaso. "Na politica dos reis de Portugal nada era deixado ao acaso em matéria de descobertas", escreve o Dr Fidelino de Figueiredo. "A descoberta do Brasil seria conseqüência lógica do plano de explorar o mundo inteiro, como se vê nas viagens portuguêsas de descobertas, as quais eram sempre delineadas com admirável unidade de propósito" (25). Considerável parte do primeiro volume da História da Colonização Portuguêsa do Brasil, é dedicada a argumentos de não haver Cabral jamais podido encontrar o Brasil por acaso. Parece que os portuguêses modernos preferem não ter tido nenhum império a possuir um pelos aventurosos métodos dos inglêses".

(23). - Naturalmente houve muitas experiências em navegar mais próximo a costa africana (E. G. Ravenstein, Journal of Vasco da Gama, páginas 190 a 192, e Roteiro de João de Castro já citadol; porém, afinál, a rota proposta por Vasco da Gama foi considerada a melhor.

(24). - The Hispanic American Historical Review, VI, 61, 62.

(25). - Gago Coutinho, Influência que as primitivas viagens portuguêsas à América do Norte tiveram sôbre o descobrimento das "Terras de Santa Cruz". (Separata do Boletim da Sociedade de Geografia de Lisboa, 1937, esp. p. 16). O almirante acredita que a própria rota de Vasco da Gama fol estabelecida anteriormente por meio de numerosas "viagens secretas". 


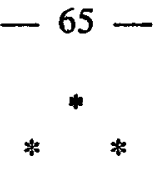

O maior argumento dos que defendem a tese da intencionalidade é que, só forte tempestade podia fazer com que a frota de Alvares Cabral se afastasse em demasia para Oeste da rota que devia seguir, segundo as instruções de Vasco da Gama, mas que isso não ocorreu porque, Pero Vaz de Caminha tão minucioso na sua carta ao rei $\mathrm{D}$. Manuel, não se refere a tempestade, o mesmo acontecendo em se tratando da missiva de Mestre João ao referido monarca.

Os que assim conjeturam laboram em grave êrro porque, como acabamos de ver pelo erudito estudo do almirante Morison, inúmeros navios de vela que procuraram dobrar o cabo da Boa Esperança sem terem sido colhidos por tempestade, avistaram terras do Brasil.

Exclusão feita dos improvisados técnicos em navegação à vela, o estudo de Morison convence qualquer pessoa de bom senso que, ventos e correntes marítimas, podiam arrastar a frota de Alvares Cabral ao litoral brasileiro.

T. O. MARCONDES DE SOUZA

Da Sociedade de Estudos Históricos de São Paulo e da Société des Américanistes de Paris.

Naturalmente, uma vez admitida a "política de sigllo" e a possibilidade de serem mantidas em segrêdo por todo tempo viagens de descobertas, - número desta pode ser multiplicado indefinidamente. Seguindo este raciocínio, a conclusão lógica é que o mundo intedro fol descoberto pelas "viagens secretas" dos portuguêses antes que Colombo realizasse alguma coisa. 